\title{
Analysis of Genotypic Variation and Selection of Superior Genotypes of Balanites roxburghii Planch. from South India
}

Guggalada Govardhana Yadav

Karnatak University Dharwad

Niranjana Murthy Hosakatte ( $\nabla$ hnmurthy60@gmail.com )

Karnatak University Dharwad https://orcid.org/0000-0002-5503-0202

\section{Research Article}

Keywords: Balanites roxburghii, Diosgenin, Fruit morphology, South India

Posted Date: August 31st, 2021

DOI: https://doi.org/10.21203/rs.3.rs-793589/v1

License: () (7) This work is licensed under a Creative Commons Attribution 4.0 International License. Read Full License 


\section{Abstract}

Balanites roxburghii is an important medicinal plant of India and is used in the treatment of various diseases and disorders. Seeds possess a high amount of oil and could be used in biodiesel production. This plant is also a source of diosgenin, a therapeutically useful compound. Domestication of this plant provides opportunities for the commercial production of those valuable products. Hence the present study was planned to assess the variability of $B$. roxburghii in Southern India and identifying the superior genotypes based on the morphological characterization. A total of 45 accessions from 35 populations were collected and variation in 9 quantitative and 3 qualitative morphological traits related to fruits was analyzed. Fruit weight showed the highest variation, ranging from $10.23 \mathrm{~g}$ in the accession KA-04C to $37.69 \mathrm{~g}$ in TN-03. Pulp weight was ranged from $1.71 \mathrm{~g}$ in KA-04C to $10.24 \mathrm{~g}$ in TN-03. Seed kernel weight was highest in TE-04 (3.87 g) followed by KA-04A (3.21 g) and TE-05A (2.98 g). PCA analysis showed that fruit weight, fruit length, fruit width, pulp weight, rind weight, and endocarp weight were the major traits contributing to the diversity. Cluster analysis resulted in the formation of 4 groups and among them, 2 accessions of clusters 3 and 6 accessions of cluster 4 showed superior fruit characters by having the highest fruit weight, pulp weight, and seed kernel weight. Accessions of these groups could be considered in future domestication programs.

\section{Introduction}

Plants are being used as a major source of nutrition and medicine. They synthesize a wide array of chemicals, which can provide various health benefits. They are also utilized in garments, fuel-wood, and feedstock for many industrial products such as timber, paper, chemicals, and biodiesel. However, a large part of the plant species has not recognized for their full potential. Such marginalized species are either semi-domesticated or wild and called 'underutilized species'. These underutilized species provide tremendous opportunities to fight against malnutrition and poverty by generating income for local people (Padulosi et al. 2013; Murthy and Bapat 2020).

Genus Balanites Delile (Zygophyllaceae) consists of several underutilized plants, traditionally used for curing various diseases and disorders and also as a food source. The Majority of the species of Balanites are distributed in the African continent. Balanites aegyptiaca is the most popular in the genus and has enormous traditional uses (Sands 2001). The fruits are eaten raw or processed to provide a variety of recipes and are considered nutritionally important due to the presence of $42.57 \%$ of carbohydrates and $9.57 \%$ of proteins with a good amount of minerals (Sands 2001; Sagna et al. 2014). The genus is characterized by a high amount of seed oil as in B. aegyptiaca (46.7\%; Chapagain et al. 2009), B. rotundifolia (31.0\%; Radunz et al. 1985), and B. wilsoniana (30.0\%; Burkill 1985), which could be used in the biodiesel production (Chapagain et al. 2009).

In India, the genus Balanites is represented by a single species, Balanites roxburghii Planch., and is distributed throughout the dry and arid lands including the peninsular region (Sands 2001). Different parts of $B$. roxburghii are used in the traditional medicine system to cure various ailments. The fruit is used to treat snakebite and deworm in children. Seeds are given in coughs and colic, and seed oil to cure burns, excoriation, and freckles (Kirtikar and Basu 1918; Nadakarni 1954). The bark is used as anti-helminthic, spasmolytic, and also in cough. Paste of the bark is used to cure skin diseases (Virendra et al. 2009).

Apart from the traditional uses, Balanites roxburghii is a good source of several valuable products. Similar to its allied species, $B$. roxburghii possesses a high amount of seed oil i.e. 40-42\% (Arora and Tak 2013) and that could be effectively utilized for the production of biodiesel (Khanvilkar et al. 2016). The different parts of $B$. roxburghii contain a good amount of diosgenin, a steroidal sapogenin used mainly as a precursor in the synthesis of most of the therapeutically useful steroidal drugs, including sex hormones and corticosteroids (Jeesus et al. 2016). Dioscorea deltoidea is the major source for the production of diosgenin in India that reported to contain $1.20 \%$ of diosgenin in its dried tuber (Nazir et al. 2021). D. deltoidea is recognized as a critically endangered species due to overexploitation and trading for the production of diosgenin (Molur and Walker 1998). Various reports proved that $B$. roxburghii possesses a good amount of diosgenin content in different parts such as root $(0.97 \%)$, stem $(0.36 \%)$, seed kernel $(0.62 \%)$, fruit pulp $(0.32 \%)$, and rind $(0.15 \%)$ and variable up to $5.6 \%$ in fruits (Varshney and Vyas 1982; Amalraj and Shankarnarayan 1987). Hence, this plant could be a good alternative for the production of diosgenin and reduce the pressure over $D$. deltoidea.

Systematic cultivation of wild plants could offer their full potential utilization (FAO 1999). Cultivation has the advantage of providing a controlled and regular supply of valuable products and protects species from the risk of extinction due to overexploitation of wild populations (Schippmann et al. 2002). To bring a species into cultivation, it is very essential to assess the genetic diversity of the species, which enables the breeders to select genotypes with desirable characters (Govindaraj et al. 2015). Assessment of genetic variability at intraspecific level is performed by various techniques such as morphological, biochemical, and DNA marker analysis (Govindaraj et al. 2015). However, comprehensive morphological diversity analysis provides a strong base to select the promising genotypes for the cultivation programs (Schlautman et al. 2020). Thus, it will be beneficial to assess the genetic diversity of $B$. roxburghii to bring the species into cultivation for sustainable exploitation to produce valuable products such as seed oil and diosgenin, to meet the global demand. Amalraj and Shankarnarayan (1987) studied the variability of $B$. roxburghii in the desert region of Rajasthan and found considerable diversity between the different genotypes. However, data on morphological diversity is lacking in the South Indian populations of $B$. roxburghii. The peninsular region of Southern India exhibits rich biodiversity and offers favorable conditions for the growth of $B$. roxburghii and the probability of obtaining intraspecific variability will be more in this region. Hence the present study has been carried out to assess the diversity of $B$. roxburghii in Southern India.

In the present study, natural populations of B. roxburghii distributed in different geographical regions of Southern India have been identified. Further, analyzed the diversity between the populations with respect to the fruit morphological characters and grouped them based on the assessed characters, and recognized the superior genotypes.

\section{Materials And Methods}

Field survey 
The present study was undertaken in the Southern region of India, including the states of Andhra Pradesh, Karnataka, Kerala, Tamil Nadu, and Telangana, during the year 2019-2021 (Figure 1; Table 1). Extensive field studies were conducted in various forest areas that cover the major geographical regions of the above-mentioned states. Natural populations of Balanites roxburghii were located based on the floristic reports, herbarium reference, and critical observation. Populations that were present in the forests or protected areas were only considered in the present study. Often, more than one type of fruit morphotypes that had considerable differences among them was identified within a single population and each morphotype was considered as an accession, and materials were collected separately for further study.

Plant material

20 Matured plants were randomly selected from each accession and 10-15 fruits were collected from each plant and pooled together for further study. A minimum distance of 20 meters was maintained between the selected plants. Fruits were collected in their ripened stage, indicated by their complete yellow color, during the months of January-March.

Morphological characterization

A total of 12 morphological traits including qualitative and quantitative, were recorded for 45 accessions of $B$. roxburghii (Table 2). Characterization of fruits was done by randomly picking 30 fruits from each accession. Pulp and rind were separated and the endocarp was broken mechanically to obtain the seed kernel. Quantitative characterization was carried out by taking measurements individually for all the selected fruits. The weight of fruit, pulp, rind, seed kernel and endocarp was recorded with the help of electronic balance and expressed in grams, whereas fruit length and fruit width were recorded using Vernier caliper and expressed in centimeters. Qualitative traits such as the shape of fruit apex and ridges on fruits were recorded by their appearances and fruit shape was assigned according to Beentje (2016). Qualitative traits were assigned with numerical values (phenotypic scores) ranging from 1 to $k$ ( $k$ equal to a number of classes), to indicate different degrees of expression (Table 2). These values were further used to compare the qualitative and quantitative data together.

Statistical analysis

Descriptive statistics such as mean, standard deviation, and standard error were calculated for each quantitative trait for each accession using Microsoft Excel 2016 and all other analyses were carried out by using IBM SPSS Statistics software version 20. Mean values and phenotypic scores were used for quantitative and qualitative traits respectively, for further analysis. Pearson correlation analysis has been carried out to find the strength of linear association between each morphological trait. Original values were standardized and Z-scores were used in the principal component analysis, to identify the prominent characteristics representing the accessions. Finally, accessions were grouped by the k-means clustering method and scores of the first two principal components were used to draw the scatter plot.

\section{Results And Discussion}

Distribution

Southern India, including the states of Andhra Pradesh, Karnataka, Kerala, Tamil Nadu, and Telangana possess considerable topographic, edaphic and climatic heterogeneity and resulted in rich biodiversity. In all the states except Kerala, we identified the natural populations of $B$. roxburghii. A total of 45 accessions from 35 natural populations were identified and the details of localities of populations and list of accessions are presented in Table 1 and Table 3. B. roxburghii is distributed throughout the dry and arid regions of Southern India, majorly concentrated in Central, Southern and Northern interiors of Karnataka, and Rayalaseema and the Eastern Ghats regions of Andhra Pradesh. Northern Telangana and North-Western Tamil Nadu regions are also major centers of distribution (Figure 1). The distributional altitude ranges from 167 to 870 meters above mean sea level (Table 1). It is a highly drought-resistant tree species, occurring mainly in scrubby and deciduous forests. It is found most often along the roadsides, banks of streams, and base of the hills where water availability is relatively high and disappears on slopes and top of the hills. Plants that grow in thick forests prefer open areas. B. roxburghii grows rich in black cotton soil, sandy soil, and red soil, but is rarely found in rocky areas.

Morphological characterization

Morphological variability is an adaptive strategy expressed by plants that allows them to be better fitted to the environment. Analysis of 12 morphological characters including the qualitative and quantitative traits (Table 2) among the 45 accessions has shown significant variability between the accessions and they are presented in Table 3. Fruit weight is the prominent trait and it was influenced by the weight of individual constituents such as pulp, rind, seed kernel, and endocarp. FWt is ranged from $10.23 \mathrm{~g}$ in the accession KA-04C to $37.69 \mathrm{~g}$ in the accession TN-03 (Table 3). More than half of the accessions (51\%) have the FWt in the range of 17 to $24 \mathrm{~g}$ and seven accessions have more than $30 \mathrm{~g}$ (KA-04A, KA-04B, KA-13A, KA-13B, TN-03, TE-04, and TE-05A; Table 3). FWt is directly affected by fruit length and fruit width. FL is ranged from $3.56 \mathrm{~cm}$ (AP-07) to $7.66 \mathrm{~cm}$ (TE-04) and FW is ranged from $2.72 \mathrm{~cm}$ (AP-01B) to $4.37 \mathrm{~cm}$ (KA-13B). Similarly, previous reports showed high variability in $B$. roxburghii with respect to fruit weight ( 6 to $80 \mathrm{~g})$, fruit length (2.6 to $8.2 \mathrm{~cm})$, and fruit width $(2.2$ to $6.3 \mathrm{~cm}$ ) among the 50 types of fruits collected in 10 locations in the desert region of Rajasthan (Amalraj and Shankarnarayan 1987). Pulp is the edible portion of the fruit, used for its medicinal and nutritional properties. It showed higher variation between the accessions, ranging from $1.71 \mathrm{~g}$ (KA-04C) to 10.24 $\mathrm{g}$ (TN-03). In some cases, percentage composition had a considerable impact on the pulp weight. For instance, accession TE-04 had the FWt of $33.41 \mathrm{~g}$ and PWt of $5.05 \mathrm{~g}$ which constitutes about $15.10 \%$ but the accession TE-09 has only $17.93 \mathrm{~g}$ of FWt, nearly half of the former one, has the PWt of $5.18 \mathrm{~g}$, which accounts for $28.91 \%$ of the fruit weight. The rind is the outer covering of the fruit, which showed less variation compared to the pulp, ranging from $2.15 \mathrm{~g}$ (KA-

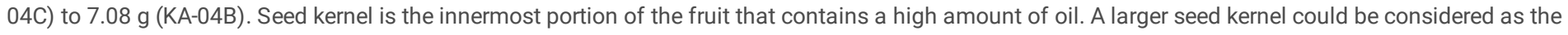
desired character to select an accession for the domestication programs. SKWt is highest in the accession TE-04 (3.87 g) followed by KA-04A (3.21 g) and TE- 
05A (2.98 g). Usually larger fruit comprise of larger seed kernel but similar to the PWt, SKWt is also affected by SK\% and it was ranged from 4.15\% (AP-02B) to $14.37 \%$ (AP-07). Endocarp constitutes about half of the fruit weight and it ranged between $4.92 \mathrm{~g}$ in accession KA-04C to $20.33 \mathrm{~g}$ in TE-04.

Among the qualitative traits studied, the fruit shape showed the highest variability among the accessions (Figure 2; Table 3). The elliptic shape is the prominent one, represented by $46.67 \%(n=21)$ of the accessions followed by obovate $(17.78 \%)$ and oblong $(11.11 \%)$ shapes. The pyriform shape of fruits is present only in TE-04 accession. Flattened type of fruit apex is the predominant character that is shown by $55.56 \%$ of the accessions and pointed type was present in few accessions (13.33\%). The majority of the accessions (68.89\%) have ridges as pale lines and very few (8.89\%) have no ridges or lines on the fruits.

Abasse et al. (2011) reported the diversity of B. aegyptiaca in Eastern Niger. Based on their results, they hypothesize that trees present in drier regions tend to produce longer and narrower seeds and heavier seed kernels and show less variability in fruit and seed width. Longer and thinner seeds provide more surface area for water absorption and larger seed kernels can store more energy for rapid seedling development, which is very essential in water-scarce regions. However, the present study revealed an abundant diversity in the fruit morphological traits among the 45 accessions distributed in different geographical locations of Southern India. Often, there was considerable difference between the accessions of the same population. This variation within a population where the environmental conditions are the same for all the plants is perhaps due to the existence of genetic variability.

Correlation between the traits

Understanding the relationship between the morphological traits could facilitate the selection of genotypes for cultivation programs. Pearson's correlation coefficients have been used to measure the strength of linear association between the traits, where the ' $r$ ' value of ' 1 ' indicates a complete positive correlation and ' -1 ' indicates a complete negative correlation (Table 4). The majority of the analyzed traits have a positive correlation with each other. Fruit weight is an important trait, which is directly influenced by individual constituents and has shown a high correlation with the PWt, RWt, SKWt, and EWt. Among them, EWt showed a very high positive correlation with FWt ( $r=0.95$ ) and had a very dominant effect on it by accounting for 37.60\% (KA-10B) to 62.65\% (AP-04) of the total weight. FWt also had a high correlation with PWt $(r=0.83)$ and RWt $(r=0.86)$. Though FL and FW have no significant correlation between them, they seem to influence the other characters. Fruits with more length tend to have high endocarp and seed kernel content whereas those with more width tend to have a high amount of pulp and rind content. $\mathrm{P} \%$ also had a significant positive correlation $(r=0.34)$ with FW. Seed kernel is another important trait, which has great commercial value because of its high oil content. It has a good correlation with FWt ( $r=0.66), \mathrm{FL}(\mathrm{r}=0.56)$, and FW ( $r=0.46)$, and thus fruit weight and its dimensions could be good indicators of large seed kernels. A similar correlation pattern of seed kernel with fruit weight ( $r=0.80)$, fruit length ( $r=0.79)$, and fruit width ( $r=0.82$ ) was reported in Prunus armeniaca (Zargar et al. 2021). However, in contrast to the present results, Abasse et al. (2011) reported the negative correlation of the seed kernel with fruit weight in Balanites aegyptiaca. But in the present study, SK\% is negatively correlated with all other traits analyzed and it indicates that the composition of seed kernel will be more in small fruits.

Quantitative and qualitative traits have a very weak correlation between them, except for the fruit length. FL had a significant positive correlation with FS and FA. As the FL increases, fruits tend to acquire round to elliptic to oblong shape and acute apex. Even though ridges/lines on the surface of the fruit won't have any correlation with other characters, fruits with no ridges are an appreciative character, because the fruits with prominent ridges have their rind deeply inserted into the pulp which makes the rind very difficult to separate from the pulp. In contrast to that, rind with no or pale ridges is easily separable. These results suggest that we can select particular genotypes for both fruit and seed kernel traits. Along with that, we can also consider selecting and improving distinct genotypes for fruit and seed kernel traits.

PCA analysis

PCA analysis was carried out to know the significant variables in the analyzed morphological traits. PCA revealed that some traits were contributed to most of the total variability that exists among the accessions. The first two principal components explained $62.74 \%$ and the first 5 principal components explained $90.50 \%$ of the total variance (Table 5). The degrees of association of traits with these axes were obtained and are presented as their Eigenvectors (Table 5). The first principal component corresponds to $43.24 \%$ of the total variance, represented by six dominant traits, FWt, FL, FW, PWt, RWt, and EWt. The second PC corresponds to $19.49 \%$ of the total variance and was represented by P\%, FS, and FA. The third PC is represented by seed kernel characteristics, SKWt and SK\%, and accounts for $12.36 \%$ of the variance. The fourth PC had the highest coefficient for FR and corresponds to $8.63 \%$ of the total variance. These results indicated that the first and second principal components explained more than half of the variance and hence characters representing these PCs are more significant in assessing the diversity of $B$. roxburghii.

\section{Clustering of accessions}

Clustering of the accessions provides details about the distribution pattern of the variables. In the present study, the resulting data were grouped using the kmeans clustering method and a scatter plot was created using the scores of the first two principal components (Figure 3). Grouping of 45 accessions resulted in the formation of 4 clusters that were closely associated with their fruit characteristics. The mean values of analyzed quantitative traits of each cluster are presented in Table 6. Cluster 1 included 19 accessions and had medium-sized fruits with FWt of $23.48 \mathrm{~g}$ and have the highest value of P\% (24.20\%) than clusters 2, 3, and 4, with the PWt of $5.59 \mathrm{~g}$ (Figure 3; Table 6). Cluster 2 included 18 accessions and it is characterized by the smallest fruits (FWt of $16.68 \mathrm{~g}$ ) among all the clusters (Figure 3; Table 6). Clusters 3 and 4 were characterized by their large fruits with the FWt of $32.29 \mathrm{~g}$ and $33.67 \mathrm{~g}$ respectively (Figure 3 ; Table 6). Even though clusters 3 and 4 have more or less equal FWt, they are distinguished by FL, FW, PWt, SKWt, P\%, and SK\%. Cluster 3 is formed by two accessions i.e KA-04A and TE-04, which had a larger seed kernel (3.54 g) and a moderate amount of PWt (5.70 g) (Figure 3; Table 6). Seed kernel has high commercial importance because of the presence of a good amount of diosgenin (0.62\%) as well as oil (40-42\%) (Varshney and Vyas 1982; Arora and Tak 2013). The present study suggests that accessions of cluster 3 could be effectively utilized for seed kernel properties. Cluster 4 included six accessions viz. KA-03, KA-04B, KA-13A, KA-13B, TN-03, and TE-05A, and had a high PWt (8.10 g) and comparatively low SKWt (2.37 g) (Figure 3; Table 6). Pulp also has 
economic importance because of the presence of a considerable amount of diosgenin (0.32\%; Varshney and Vyas 1982). Hence accessions of cluster 4 could be effectively utilized in future domestication programs for their pulp characteristics. And also, these results prove the correlation pattern that high FL favors the larger seeds and high FW favors the more amount of pulp content (Table 4). Thus, the accessions of clusters 3 and 4 could be utilized for future cultivation programs in general and accessions of cluster 3 for seed kernel traits and accessions of cluster 4 for pulp traits in particular.

\section{Conclusion}

Balanites roxburghii is an underutilized medicinal tree in India, used to cure various diseases and disorders. This species is also a source of several valuable products such as diosgenin and seed oil. It is advantageous to use this species sustainably for the production of those valuable products. The present study was undertaken to assess the diversity of $B$. roxburghii in Southern India and it revealed the existence of a large amount of variability in South Indian populations. Among the 45 accessions studied, accessions of clusters 3 (KA-04A and TE-04) and cluster 4 (KA-03, KA-04B, KA-13A, KA-13B, TN-03, and TE05A) have superior fruit qualities with respect to pulp and seed kernel content and could be used in the future cultivation programs. The majority of the areas where the $B$. roxburghii is distributed, receive very little rainfall and have low irrigation facilities and suitable soil conditions. It could be grown commercially in those areas, to get valuable products and generate income for local people. Diversity within the population is common in $B$. roxburghii, where the environmental conditions are the same for all plants, is perhaps due to genetic variability. However, further analysis is needed on the variability of fruit yield, tree height, canopy area, and other morphological traits along with the effect of geographic, environmental, and genetic factors on the phenotypic variability. That could assist the geneticists and breeders in identifying, selecting, and improving the genotypes for various cultivation programs.

\section{Declarations}

\section{Conflict of Interest/Ethical Intrest}

The authors declare no conflict of interest. This article does not contain any studies involving animals performed by any of the authors.

\section{References}

Abasse T, Weber JC, Katkore B, Boureima M, Larwanou M, Kalinganire A (2011) Morphological variation in Balanites aegyptiaca fruits and seeds within and among parkland agroforests in eastern Niger. Agroforest Syst 81:57-66

Amalraj VA, Shankarnarayan KA (1987) Variability in Balanites roxburghii PI. in the Indian desert. J Bombay Nat Hist Soc 84:476-478

Arora A, Tak L (2013) Balanites roxburghii: Physico-chemical properties and composition of fatty acid from arid zone of Rajasthan. Int J Basic Appl Chem Sci $3(2): 1-5$

Beentje H (2016) The Kew plant glossary: An illustrated dictionary of plant terms. $2^{\text {nd }}$ edn. Royal Botanic Gardens, Kew, UK

Burkill HM (1985) The useful plants of West Tropical Africa, Vol.1, Families A-D, Royal Botanic Gardens, Kew, UK

Chapagain BP, Yehoshua Y, Wiesman Z (2009) Desert date (Balanites aegyptiaca) as an arid lands sustainable bioresource for biodiesel. Bioresour Technol 100:1221-1226

FAO (1999) Use and potential of wild plants in farm households. Food and Agriculture Organization of the United Nations, Viale delle Terme di Caracalla, Rome, Italy.

Govindaraj M, Vetriventhan M, Srinivasan M (2015) Importance of genetic diversity assessment in crop plants and its recent advances: An overview of its analytical perspectives. Genet Res Int 2015: Article ID 431487 http://dx.doi.org/10.1155/2015/431487

Jesus M, Martins APJ, Gallardo E, Silvestre S (2016) Diosgenin: Recent highlights on pharmacology and analytical methodology. J Anal Methods Chem 2016:Article ID 4156293 http://dx.doi.org/10.1155/2016/4156293

Khanvilkar P, Patel G, Nagar PS, Shah SN (2016) Balanites roxburghii plant oil as potential non-edible feedstock for biodiesel production. Energy Power 6:21-27 Kirtikar KR, Basu BD (1918) Indian medicinal plants vol.1, part.1, Suduindranath Basu, Panini office, Bhuwaneswari asrama, Bahadurganj, India

Molur S, Walker S (1998) Report of the workshop on "Conservation assessment and management plan for selected medicinal plant species of Northern, Northeastern and Central India (BCPP- Endangered Species Project). Zoo Outreach Organisation, Conservation Breeding Specialists Group, India, Coimbatore, India

Murthy HN, Bapat VA (2020) Importance of underutilized fruits and nuts. In Murthy HN, Bapat VA (eds) Bioactive compounds in underutilized fruits and nuts. Reference series in phytochemistry, Springer, Cham, Switzerland, pp 3-19

Nadakarni KM (1954) Indian materia medica, $3^{\text {rd }}$ edn. Bombay Popular Prakashan, Mumbai, India

Nazir R, Pandey DK, Pandey B, Kumar V, Dwivedi P, Khampariya A, Dey A, Malik T (2021) Optimization of diosgenin extraction from Dioscorea deltoidea tubers using response surface methodology and artificial neural network modelling. PLoS One 16:e0253617 https://doi.org/10.1371/journal.pone.0253617 
Padulosi S, Thompson J, Rudebjer P (2013) Fighting poverty, hunger and malnutrition with neglected and underutilized species (NUS): Needs, challenges and the way forward. Bioversity International, Rome, Italy

Radunz A, Grosse W, Mewi-Sutz J (1985) Seeds of the East African savannah bush Balanites orbicularis as a possible new source of lipids for commercial use. J Am Oil Chem Soc 62:1251-1252

Sagna MB, Diallo A, Sarr PS, Ndiaye O, Goffner D, Guisse A (2014) Biochemical composition and nutritional value of Balanites aegyptiaca (L.) Del fruit pulps from Northern Ferlo in Senegal. Afr J of Biotechnol 13:336-342

Sands MJS (2001) The Desert date and its relatives: A revision of the genus Balanites. Kew Bull 56:1-128

Schippmann U, Leaman DJ, Cunningham AB (2002) Impact of Cultivation and Gathering of Medicinal Plants on Biodiversity: Global Trends and Issues. Food and Agriculture Organization of the United Nations, Rome, Italy

Schlautman B, Diaz-Garcia L, Barriball S (2020) Morphometric approaches to promote the use of exotic germplasm for improved food security and resilience to climate change: A kura clover example. Plant Sci 290: https://doi.org/10.1016/j.plantsci.2019.110319

Varshney IP, Vyas P (1982) Saponin and sapogenin contents of Balanites roxburghii. Int J Crude Drug Res 20:3-7

Virendra S, Priyanka T, Patel JR, Kori ML and Dixit VK (2009) Preliminary phytochemical and antiasthmatic studies on stem bark of Balanites roxburghii Planch. Int J Pharm Clin Res 1: 40-42

Zargar SA, Wani AA, Saggoo MIS (2021) Analysis of phenotypic diversity of apricot (Prunus armeniaca L.) accessions from Jammu and Kashmir, India. Plant Genet Resour. doi:10.1017/S1479262121000241

\section{Tables}

Table 1. Geographical locations of populations of Balanites roxburghii distributed in Southern India. 


\begin{tabular}{|c|c|c|c|c|c|c|}
\hline State & Population & Location & District & Lattitude & Longitude & Altitude (m) \\
\hline \multirow[t]{9}{*}{ Andhra Pradesh } & AP-01 & Giddangivaripalli & Kadapa & $14^{\circ} 18^{\prime} 14.07^{\prime \prime} \mathrm{N}$ & $78^{\circ} 19^{\prime} 28.46^{\prime \prime} \mathrm{E}$ & 362 \\
\hline & AP-02 & Jaladurgam & Kurnool & $15^{\circ} 15^{\prime} 06.25^{\prime \prime} \mathrm{N}$ & $77^{\circ} 53^{\prime} 42.56^{\prime \prime} \mathrm{E}$ & 412 \\
\hline & AP-03 & Kallampalli & Anantapuram & $13^{\circ} 55^{\prime} 15.82^{\prime \prime} \mathrm{N}$ & $77^{\circ} 38^{\prime} 48.29 " \mathrm{E}$ & 697 \\
\hline & AP-04 & Omkar Temple & Kurnool & $15^{\circ} 36^{\prime} 08.45^{\prime \prime} \mathrm{N}$ & $78^{\circ} 36^{\prime} 37.95^{\prime \prime} \mathrm{E}$ & 236 \\
\hline & AP-05 & Pacherla & Kurnool & $15^{\circ} 25^{\prime} 36.85^{\prime \prime} \mathrm{N}$ & $78^{\circ} 43^{\prime} 42.76^{\prime \prime} \mathrm{E}$ & 320 \\
\hline & AP-06 & Rachepalli & Kadapa & $14^{\circ} 12^{\prime} 48.74^{\prime \prime} \mathrm{N}$ & $78^{\circ} 49^{\prime} 30.19^{\prime \prime} \mathrm{E}$ & 324 \\
\hline & AP-07 & Siddapuram & Kurnool & $15^{\circ} 49^{\prime} 46.15^{\prime \prime} \mathrm{N}$ & $78^{\circ} 40^{\prime} 07.99^{\prime \prime} \mathrm{E}$ & 285 \\
\hline & AP-08 & Thummalabailu & Prakasam & $15^{\circ} 58^{\prime} 36.93^{\prime \prime} \mathrm{N}$ & $78^{\circ} 54^{\prime} 09.13^{\prime \prime} \mathrm{E}$ & 656 \\
\hline & AP-09 & Venkatagaripalli & Anantapuram & $14^{\circ} 06^{\prime} 13.65^{\prime \prime} \mathrm{N}$ & $77^{\circ} 44^{\prime} 15.52^{\prime \prime} \mathrm{E}$ & 508 \\
\hline \multirow[t]{14}{*}{ Karnataka } & $\mathrm{KA}-01$ & Amareshwara & Raichur & $16^{\circ} 15^{\prime} 50.96^{\prime \prime} \mathrm{N}$ & $76^{\circ} 32^{\prime} 35.95^{\prime \prime} \mathrm{E}$ & 444 \\
\hline & $\mathrm{KA}-02$ & Bannerghatta & Bengaluru rural & $12^{\circ} 42^{\prime} 22.54^{\prime \prime} \mathrm{N}$ & $77^{\circ} 34^{\prime} 55.56 " \mathrm{E}$ & 806 \\
\hline & KA-03 & Chennagiri & Davanagere & $13^{\circ} 58^{\prime} 04.89^{\prime \prime} \mathrm{N}$ & $76^{\circ} 01^{\prime} 46.17^{\prime \prime} \mathrm{E}$ & 732 \\
\hline & KA-04 & Chowdlapura & Tumakuru & $13^{\circ} 19^{\prime} 21.80^{\prime \prime} \mathrm{N}$ & $76^{\circ} 43^{\prime} 50.49^{\prime \prime} \mathrm{E}$ & 870 \\
\hline & KA-05 & Gudibande & Chikkaballapura & $13^{\circ} 41^{\prime} 58.25^{\prime \prime} \mathrm{N}$ & $77^{\circ} 41^{\prime} 50.87^{\prime \prime} \mathrm{E}$ & 844 \\
\hline & KA-06 & Jenukallupalya & Ramanagara & $12^{\circ} 52^{\prime} 22.15^{\prime \prime} \mathrm{N}$ & $77^{\circ} 14^{\prime} 03.19^{\prime \prime} \mathrm{E}$ & 837 \\
\hline & $\mathrm{KA}-07$ & Kalinganahalli & Tumakuru & $13^{\circ} 34^{\prime} 14.44^{\prime \prime} \mathrm{N}$ & $76^{\circ} 48^{\prime} 28.43^{\prime \prime} \mathrm{E}$ & 756 \\
\hline & KA-08 & Kappathagudda & Gadaga & $15^{\circ} 13^{\prime} 14.34^{\prime \prime} \mathrm{N}$ & $75^{\circ} 42^{\prime} 31.29^{\prime \prime} \mathrm{E}$ & 674 \\
\hline & KA-09 & Malebennuru & Davanagere & $14^{\circ} 19^{\prime} 02.64^{\prime \prime} \mathrm{N}$ & $75^{\circ} 42^{\prime} 34.64^{\prime \prime} \mathrm{E}$ & 637 \\
\hline & $\mathrm{KA}-10$ & Moka & Ballari & $15^{\circ} 15^{\prime} 18.55^{\prime \prime} \mathrm{N}$ & $77^{\circ} 04^{\prime} 16.36^{\prime \prime} \mathrm{E}$ & 406 \\
\hline & $\mathrm{KA}-11$ & Ranebennuru & Haveri & $14^{\circ} 38^{\prime} 50.06^{\prime \prime} \mathrm{N}$ & $75^{\circ} 41^{\prime} 01.61^{\prime \prime} \mathrm{E}$ & 585 \\
\hline & $\mathrm{KA}-12$ & Ratnapura & Raichur & $15^{\circ} 51^{\prime} 18.95^{\prime \prime} \mathrm{N}$ & $76^{\circ} 29^{\prime} 27.22^{\prime \prime} \mathrm{E}$ & 495 \\
\hline & KA-13 & Shiruguppi & Bagalakote & $16^{\circ} 14^{\prime} 58.74^{\prime \prime} \mathrm{N}$ & $75^{\circ} 47^{\prime} 16.88^{\prime \prime} \mathrm{E}$ & 545 \\
\hline & $\mathrm{KA}-14$ & Thondala & Kolara & $13^{\circ} 10^{\prime} 57.82^{\prime \prime} \mathrm{N}$ & $78^{\circ} 14^{\prime} 49.33^{\prime \prime} \mathrm{E}$ & 814 \\
\hline \multirow[t]{3}{*}{ Tamil Nadu } & TN-01 & Chinna Sakkanavaram & Krishnagiri & $12^{\circ} 41^{\prime} 23.83^{\prime \prime} \mathrm{N}$ & $78^{\circ} 14^{\prime} 29.53^{\prime \prime} \mathrm{E}$ & 620 \\
\hline & TN-02 & Coimbatore & Coimbatore & $11^{\circ} 01^{\prime} 06.61^{\prime \prime} \mathrm{N}$ & $76^{\circ} 56^{\prime} 37.91^{\prime \prime} \mathrm{E}$ & 436 \\
\hline & TN-03 & Madhanakuppam & Krishnagiri & $12^{\circ} 35^{\prime} 34.08^{\prime \prime} \mathrm{N}$ & $78^{\circ} 19^{\prime} 21.72^{\prime \prime} \mathrm{E}$ & 527 \\
\hline \multirow[t]{9}{*}{ Telangana } & TE-01 & Bornapalli & Jagtial & $19^{\circ} 03^{\prime} 33.41^{\prime \prime} \mathrm{N}$ & $78^{\circ} 49^{\prime} 51.36^{\prime \prime} \mathrm{E}$ & 202 \\
\hline & TE-02 & Buddharam & Mancherial & $18^{\circ} 56^{\prime} 19.61^{\prime \prime} \mathrm{N}$ & $79^{\circ} 42^{\prime} 39.07^{\prime \prime} \mathrm{E}$ & 167 \\
\hline & TE-03 & Burugpet & Bhupalapalli & $18^{\circ} 20^{\prime} 10.90^{\prime \prime} \mathrm{N}$ & $80^{\circ} 04^{\prime} 14.94^{\prime \prime} \mathrm{E}$ & 198 \\
\hline & TE-04 & DoravariVempalli & Mahabubabad & $17^{\circ} 55^{\prime} 06.68^{\prime \prime} \mathrm{N}$ & $80^{\circ} 10^{\prime} 17.38^{\prime \prime} \mathrm{E}$ & 321 \\
\hline & TE-05 & Katapuram & Mulugu & $18^{\circ} 08^{\prime} 13.44^{\prime \prime} \mathrm{N}$ & $80^{\circ} 21^{\prime} 53.86^{\prime \prime} \mathrm{E}$ & 209 \\
\hline & TE-06 & Pegadapalli & Mulugu & $18^{\circ} 06^{\prime} 33.94^{\prime \prime} \mathrm{N}$ & $80^{\circ} 03^{\prime} 26.28^{\prime \prime} \mathrm{E}$ & 204 \\
\hline & TE-07 & Pocharam & Medak & $18^{\circ} 06^{\prime} 42.18^{\prime \prime} \mathrm{N}$ & $78^{\circ} 13^{\prime} 01.50^{\prime \prime} \mathrm{E}$ & 464 \\
\hline & TE-08 & Talamalla & Mancherial & $18^{\circ} 59^{\prime} 32.34^{\prime \prime} \mathrm{N}$ & $79^{\circ} 15^{\prime} 42.11^{\prime \prime} \mathrm{E}$ & 239 \\
\hline & TE-09 & Udumpur & Adilabad & $19^{\circ} 11^{\prime} 55.28^{\prime \prime} \mathrm{N}$ & $78^{\circ} 54^{\prime} 13.97^{\prime \prime} \mathrm{E}$ & 247 \\
\hline
\end{tabular}

\section{Table 2. Morphological traits used for the variability analysis of Balanites roxburghii accessions.}




\begin{tabular}{|c|c|c|c|c|}
\hline & Trait & Phenotype code & Description & Phenotype score \\
\hline \multicolumn{5}{|c|}{ Qualitative traits } \\
\hline \multirow{6}{*}{1.} & \multirow[t]{6}{*}{ Fruit shape } & \multirow[t]{6}{*}{ FS } & \multirow[t]{6}{*}{ The shape of matured fruit } & 1. Round \\
\hline & & & & 2. Elliptic \\
\hline & & & & 3. Ovate \\
\hline & & & & 4. Obovate \\
\hline & & & & 5. Oblong \\
\hline & & & & 6. Pyriform \\
\hline \multirow{3}{*}{1.} & \multirow[t]{3}{*}{ Fruit apex } & \multirow[t]{3}{*}{ FA } & \multirow[t]{3}{*}{ The appearance of the apex of the fruit } & 1. Flattened \\
\hline & & & & 2. Round \\
\hline & & & & 3. Acute \\
\hline \multirow{3}{*}{1.} & \multirow[t]{3}{*}{ Ridges on fruit } & \multirow[t]{3}{*}{$\mathrm{FR}$} & \multirow[t]{3}{*}{ Ridges/lines on the surface of the fruit } & 1. Absent \\
\hline & & & & 2. Pale \\
\hline & & & & 3. Prominent \\
\hline \multicolumn{5}{|c|}{ Quantitative traits } \\
\hline 1. & Fruit weight & FWt & Measured in gram & - \\
\hline 1. & Fruit length & $\mathrm{FL}$ & Measured in $\mathrm{cm}$ & - \\
\hline 1. & Fruit width & FW & Measured in $\mathrm{cm}$ & - \\
\hline 1 & Pulp weight & PWt & Measured in gram & - \\
\hline & Rind weight & RWt & Measured in gram & - \\
\hline 1. & Seed Kernel weight & SKWt & Measured in gram & - \\
\hline 1 & Endocarp weight & EWt & Measured in gram & - \\
\hline 1. & $\%$ Composition of pulp & $\mathrm{P} \%$ & Per 100 grams of fruit & - \\
\hline 1. & $\%$ Composition of seed & SK\% & Per 100 grams of fruit & - \\
\hline
\end{tabular}

Table 3. Variability in qualitative and quantitative traits of different accessions of Balanites roxburghii 


\begin{tabular}{|c|c|c|c|c|c|c|c|c|c|c|c|}
\hline $\begin{array}{l}\text { Accession } \\
\text { number }\end{array}$ & Accession & FWt (g) & $\mathrm{FL}(\mathrm{cm})$ & $\mathrm{FW}(\mathrm{cm})$ & PWt (g) & RWt (g) & SKWt (g) & EWt (g) & $\mathrm{P} \%(\%)$ & SK\% (\%) & $\mathrm{F}$ \\
\hline 1. & AP-01A & $23.12 \pm 1.13$ & $4.73 \pm 0.13$ & $3.50 \pm 0.09$ & $5.98 \pm 0.50$ & $3.51 \pm 0.19$ & $1.30 \pm 0.09$ & $12.34 \pm 0.66$ & $25.87 \pm 1.64$ & $5.62 \pm 0.38$ & 5 \\
\hline 1. & AP-01B & $15.23 \pm 0.89$ & $5.04 \pm 0.09$ & $2.72 \pm 0.10$ & $3.05 \pm 0.45$ & $2.32 \pm 0.17$ & $0.80 \pm 0.07$ & $9.01 \pm 0.39$ & $20.01 \pm 1.61$ & $5.27 \pm 0.58$ & 5 \\
\hline 1. & AP-02A & $21.80 \pm 0.70$ & $4.97 \pm 0.07$ & $3.58 \pm 0.07$ & $6.05 \pm 0.38$ & $3.09 \pm 0.13$ & $2.24 \pm 0.20$ & $10.40 \pm 0.69$ & $27.73 \pm 0.78$ & $10.28 \pm 0.28$ & 2 \\
\hline 1. & AP-02B & $18.66 \pm 0.93$ & $3.68 \pm 0.06$ & $3.56 \pm 0.07$ & $5.17 \pm 0.34$ & $3.47 \pm 0.22$ & $0.77 \pm 0.13$ & $9.25 \pm 0.34$ & $27.71 \pm 0.88$ & $4.15 \pm 0.63$ & 1 \\
\hline 1. & AP-03 & $17.25 \pm 0.62$ & $3.93 \pm 0.06$ & $3.45 \pm 0.05$ & $4.32 \pm 0.22$ & $3.18 \pm 0.15$ & $1.52 \pm 0.10$ & $8.15 \pm 0.26$ & $25.04 \pm 0.49$ & $8.81 \pm 0.68$ & 2 \\
\hline 1. & AP-04 & $16.52 \pm 0.65$ & $3.75 \pm 0.10$ & $3.16 \pm 0.05$ & $2.49 \pm 0.12$ & $2.75 \pm 0.20$ & $1.71 \pm 0.10$ & $10.35 \pm 0.29$ & $15.05 \pm 0.50$ & $10.35 \pm 0.40$ & 2 \\
\hline 1. & AP-05 & $17.10 \pm 0.60$ & $3.80 \pm 0.11$ & $3.20 \pm 0.12$ & $2.84 \pm 0.20$ & $2.57 \pm 0.15$ & $1.97 \pm 0.15$ & $9.59 \pm 0.20$ & $16.62 \pm 0.61$ & $11.50 \pm 0.44$ & 4 \\
\hline 1. & AP-06 & $22.66 \pm 0.89$ & $5.28 \pm 0.14$ & $3.32 \pm 0.05$ & $4.29 \pm 0.16$ & $3.44 \pm 0.21$ & $2.12 \pm 0.19$ & $12.80 \pm 0.77$ & $18.95 \pm 0.81$ & $9.36 \pm 0.65$ & 2 \\
\hline 1. & AP-07 & $17.21 \pm 0.47$ & $3.56 \pm 0.04$ & $3.09 \pm 0.03$ & $2.94 \pm 0.15$ & $2.71 \pm 0.20$ & $2.47 \pm 0.10$ & $9.06 \pm 0.21$ & $17.06 \pm 0.35$ & $14.37 \pm 0.28$ & 2 \\
\hline 1. & AP-08 & $21.60 \pm 0.73$ & $5.08 \pm 0.15$ & $3.35 \pm 0.04$ & $3.89 \pm 0.25$ & $3.68 \pm 0.23$ & $2.24 \pm 0.13$ & $11.81 \pm 0.32$ & $18.01 \pm 0.64$ & $10.37 \pm 0.42$ & 2 \\
\hline 1. & AP-09 & $15.52 \pm 058$ & $3.67 \pm 0.07$ & $3.28 \pm 0.05$ & $2.61 \pm 0.19$ & $3.09 \pm 0.10$ & $1.61 \pm 0.13$ & $8.21 \pm 0.54$ & $16.80 \pm 1.03$ & $10.37 \pm 1.00$ & 2 \\
\hline 1. & KA-01 & $19.73 \pm 1.28$ & $4.56 \pm 0.17$ & $3.47 \pm 0.12$ & $3.74 \pm 0.50$ & $4.76 \pm 0.44$ & $1.55 \pm 0.10$ & $9.69 \pm 0.37$ & $18.94 \pm 0.93$ & $7.88 \pm 0.55$ & 2 \\
\hline 1. & KA-02 & $22.04 \pm 1.02$ & $5.37 \pm 0.11$ & $3.50 \pm 0.08$ & $6.57 \pm 0.32$ & $3.82 \pm 0.25$ & $2.13 \pm 0.15$ & $9.66 \pm 0.35$ & $29.79 \pm 0.36$ & $9.67 \pm 0.70$ & 5 \\
\hline 1. & KA-03 & $29.57 \pm 0.71$ & $5.19 \pm 0.07$ & $3.92 \pm 0.04$ & $7.33 \pm 0.29$ & $5.26 \pm 0.12$ & $2.51 \pm 0.14$ & $14.46 \pm 0.47$ & $24.80 \pm 0.98$ & $8.49 \pm 0.35$ & 3 \\
\hline 1. & $\mathrm{KA}-04 \mathrm{~A}$ & $31.17 \pm 1.02$ & $5.28 \pm 0.13$ & $3.86 \pm 0.05$ & $6.34 \pm 0.19$ & $4.67 \pm 0.16$ & $3.21 \pm 0.17$ & $16.90 \pm 0.64$ & $20.34 \pm 0.33$ & $10.31 \pm 0.48$ & 4 \\
\hline 1. & KA-04B & $34.98 \pm 1.58$ & $5.17 \pm 0.19$ & $4.31 \pm 0.09$ & $8.39 \pm 0.67$ & $7.08 \pm 0.40$ & $2.65 \pm 0.19$ & $16.83 \pm 0.67$ & $23.99 \pm 1.13$ & $7.58 \pm 0.51$ & 1 \\
\hline 1. & KA-04C & $10.23 \pm 0.37$ & $4.09 \pm 0.09$ & $2.74 \pm 0.04$ & $1.71 \pm 0.09$ & $2.15 \pm 0.07$ & $1.45 \pm 0.06$ & $4.92 \pm 0.18$ & $16.68 \pm 0.33$ & $14.20 \pm 0.48$ & 2 \\
\hline 1. & KA-04D & $13.59 \pm 0.59$ & $3.66 \pm 0.15$ & $3.03 \pm 0.05$ & $2.66 \pm 0.17$ & $3.19 \pm 0.23$ & $1.48 \pm 0.08$ & $6.25 \pm 0.23$ & $19.61 \pm 0.85$ & $10.86 \pm 0.59$ & 2 \\
\hline 1. & KA-05 & $23.26 \pm 1.00$ & $4.91 \pm 0.08$ & $3.58 \pm 0.06$ & $5.17 \pm 0.2$ & $4.13 \pm 0.21$ & $2.51 \pm 0.16$ & $11.47 \pm 0.43$ & $22.23 \pm 0.29$ & $10.79 \pm 0.40$ & 2 \\
\hline 1. & KA-06 & $20.55 \pm 0.69$ & $4.37 \pm 0.04$ & $3.48 \pm 0.05$ & $6.11 \pm 0.26$ & $3.56 \pm 0.15$ & $1.99 \pm 0.10$ & $8.89 \pm 0.22$ & $29.74 \pm 0.33$ & $9.67 \pm 1.53$ & 3 \\
\hline 1. & KA-07 & $17.52 \pm 0.66$ & $3.91 \pm 0.04$ & $3.29 \pm 0.06$ & $4.57 \pm 0.20$ & $3.45 \pm 0.13$ & $1.34 \pm 0.12$ & $8.16 \pm 0.31$ & $26.11 \pm 0.52$ & $7.67 \pm 0.47$ & 5 \\
\hline 1. & KA-08 & $15.83 \pm 0.71$ & $3.90 \pm 0.06$ & $3.29 \pm 0.04$ & $2.87 \pm 0.20$ & $2.81 \pm 0.18$ & $1.93 \pm 0.07$ & $8.23 \pm 0.60$ & $18.11 \pm 0.83$ & $12.18 \pm 0.57$ & 2 \\
\hline 1. & KA-09 & $16.29 \pm 0.65$ & $3.82 \pm 0.03$ & $3.46 \pm 0.05$ & $3.67 \pm 0.19$ & $3.49 \pm 0.15$ & $1.13 \pm 0.05$ & $8.00 \pm 0.27$ & $22.51 \pm 0.59$ & $6.96 \pm 0.22$ & 1 \\
\hline 1. & KA-10A & $22.94 \pm 0.67$ & $5.48 \pm 0.06$ & $3.46 \pm 0.05$ & $6.31 \pm 0.27$ & $3.94 \pm 0.16$ & $1.61 \pm 0.07$ & $11.09 \pm 0.29$ & $27.49 \pm 0.58$ & $7.01 \pm 0.31$ & 2 \\
\hline 1. & $\mathrm{KA}-10 \mathrm{~B}$ & $20.32 \pm 0.90$ & $3.72 \pm 0.08$ & $3.86 \pm 0.04$ & $7.24 \pm 0.37$ & $3.04 \pm 0.10$ & $2.39 \pm 0.18$ & $7.64 \pm 0.35$ & $35.62 \pm 0.89$ & $11.77 \pm 0.58$ & 1 \\
\hline 1. & $\mathrm{KA}-11$ & $20.30 \pm 1.03$ & $3.81 \pm 0.07$ & $3.60 \pm 0.07$ & $5.10 \pm 0.23$ & $4.25 \pm 0.12$ & $1.62 \pm 0.11$ & $9.32 \pm 0.80$ & $25.13 \pm 0.99$ & $7.99 \pm 0.31$ & 1 \\
\hline 1. & KA-12 & $25.38 \pm 0.86$ & $4.54 \pm 005$ & $3.83 \pm 0.06$ & $4.93 \pm 0.26$ & $4.48 \pm 0.14$ & $2.24 \pm 0.12$ & $13.73 \pm 0.51$ & $19.42 \pm 0.59$ & $8.83 \pm 0.35$ & 4 \\
\hline 1. & $K A-13 A$ & $32.48 \pm 2.58$ & $6.27 \pm 0.20$ & $3.67 \pm 0.08$ & $6.98 \pm 0.67$ & $6.61 \pm 0.60$ & $1.62 \pm 0.10$ & $17.28 \pm 5.53$ & $21.50 \pm 0.92$ & $4.91 \pm 0.95$ & 2 \\
\hline & KA-13B & $30.91 \pm 2.88$ & $4.80 \pm 0.18$ & $4.37 \pm 0.13$ & $7.07 \pm 0.72$ & $6.23 \pm 0.77$ & $2.03 \pm 0.26$ & $15.54 \pm 1.82$ & $22.89 \pm 2.75$ & $6.58 \pm 0.66$ & 3 \\
\hline
\end{tabular}




\begin{tabular}{|c|c|c|c|c|c|c|c|c|c|c|c|}
\hline 1. & $\mathrm{KA}-14$ & $16.30 \pm 0.72$ & $4.18 \pm 0.05$ & $3.28 \pm 0.06$ & $2.62 \pm 0.21$ & $3.47 \pm 0.24$ & $1.63 \pm 0.11$ & $8.59 \pm 0.42$ & $16.07 \pm 1.20$ & $10.00 \pm 0.84$ & 4 \\
\hline 1. & TN-01 & $17.61 \pm 0.44$ & $3.76 \pm 0.03$ & $3.30 \pm 0.05$ & $3.87 \pm 0.12$ & $3.60 \pm 0.21$ & $1.51 \pm 0.12$ & $8.52 \pm 0.20$ & $21.98 \pm 0.57$ & $8.57 \pm 0.51$ & 3 \\
\hline 1. & TN-02 & $26.71 \pm 0.95$ & $5.27 \pm 0.08$ & $3.90 \pm 0.07$ & $6.04 \pm 0.26$ & $5.20 \pm 0.30$ & $2.54 \pm 0.14$ & $12.69 \pm 0.41$ & $22.60 \pm 0.44$ & $9.50 \pm 0.30$ & 2 \\
\hline 1. & TN-03 & $37.69 \pm 0.94$ & $5.21 \pm 0.05$ & $4.26 \pm 0.05$ & $10.24 \pm 0.52$ & $6.83 \pm 0.18$ & $2.47 \pm 0.13$ & $18.15 \pm 0.41$ & $27.18 \pm 1.30$ & $6.55 \pm 0.36$ & 2 \\
\hline 1. & TE-01 & $26.14 \pm 1.25$ & $5.16 \pm 0.07$ & $3.44 \pm 0.06$ & $5.66 \pm 0.42$ & $3.51 \pm 0.16$ & $1.96 \pm 0.11$ & $15.00 \pm 0.76$ & $21.67 \pm 0.82$ & $7.52 \pm 0.76$ & 4 \\
\hline 1. & TE-02 & $28.50 \pm 1.10$ & $5.70 \pm 0.30$ & $3.80 \pm 0.22$ & $4.99 \pm 0.32$ & $4.18 \pm 0.21$ & $2.37 \pm 0.16$ & $16.82 \pm 0.60$ & $17.50 \pm 0.55$ & $8.30 \pm 0.36$ & 4 \\
\hline 1. & TE-03 & $28.11 \pm 0.92$ & $5.35 \pm 0.40$ & $3.46 \pm 0.19$ & $4.72 \pm 0.48$ & $4.17 \pm 0.45$ & $2.34 \pm 0.29$ & $16.90 \pm 0.87$ & $16.79 \pm 0.87$ & $8.32 \pm 0.92$ & 5 \\
\hline 1. & TE-04 & $33.41 \pm 0.92$ & $7.66 \pm 0.19$ & $3.43 \pm 0.05$ & $5.05 \pm 0.25$ & $4.16 \pm 0.13$ & $3.87 \pm 0.15$ & $20.33 \pm 0.51$ & $15.10 \pm 0.47$ & $11.59 \pm 0.40$ & 6 \\
\hline 1. & TE-05A & $36.38 \pm 0.91$ & $6.63 \pm 0.05$ & $3.72 \pm 0.06$ & $8.58 \pm 0.24$ & $6.48 \pm 0.25$ & $2.98 \pm 0.19$ & $18.33 \pm 0.44$ & $23.57 \pm 0.36$ & $8.20 \pm 0.46$ & 4 \\
\hline 1. & TE-05B & $19.69 \pm 1.50$ & $4.63 \pm 0.15$ & $3.26 \pm 0.09$ & $4.45 \pm 0.30$ & $3.17 \pm 0.20$ & $1.89 \pm 0.22$ & $10.17 \pm 0.50$ & $22.61 \pm 0.88$ & $9.60 \pm 0.98$ & 2 \\
\hline 1. & TE-06A & $22.01 \pm 1.08$ & $4.98 \pm 0.06$ & $3.52 \pm 0.06$ & $5.51 \pm 0.27$ & $3.46 \pm 0.15$ & $2.03 \pm 0.18$ & $11.00 \pm 0.69$ & $25.03 \pm 1.03$ & $9.22 \pm 0.59$ & 2 \\
\hline 1. & TE-06B & $18.07 \pm 1.01$ & $5.34 \pm 0.12$ & $3.04 \pm 0.08$ & $4.15 \pm 0.15$ & $3.45 \pm 0.17$ & $1.63 \pm 0.13$ & $8.84 \pm 0.70$ & $22.97 \pm 1.08$ & $9.02 \pm 0.24$ & 5 \\
\hline 1. & TE-07A & $25.48 \pm 0.47$ & $4.32 \pm 0.07$ & $3.77 \pm 0.04$ & $5.61 \pm 0.20$ & $4.54 \pm 0.13$ & $1.52 \pm 0.15$ & $13.72 \pm 0.34$ & $22.02 \pm 0.70$ & $5.97 \pm 0.50$ & 2 \\
\hline 1. & TE-07B & $21.19 \pm 0.69$ & $3.87 \pm 0.03$ & $3.42 \pm 0.04$ & $6.48 \pm 0.34$ & $2.77 \pm 0.10$ & $2.36 \pm 0.18$ & $9.59 \pm 0.31$ & $30.56 \pm 0.89$ & $11.12 \pm 0.62$ & 2 \\
\hline 1. & TE-08 & $23.99 \pm 1.09$ & $5.07 \pm 0.17$ & $3.47 \pm 0.06$ & $5.65 \pm 0.38$ & $3.50 \pm 0.15$ & $2.62 \pm 0.10$ & $12.21 \pm 0.60$ & $23.56 \pm 0.58$ & $10.94 \pm 0.49$ & 4 \\
\hline 1. & TE-09 & $17.93 \pm 0.61$ & $4.80 \pm 0.08$ & $3.17 \pm 0.06$ & $5.18 \pm 0.26$ & $2.94 \pm 0.12$ & $1.06 \pm 0.05$ & $8.73 \pm 0.34$ & $28.91 \pm 0.95$ & $5.91 \pm 0.17$ & 2 \\
\hline
\end{tabular}

Table 4. Pearson's correlation matrix for the morphological traits used to assess the diversity of Balanites roxburghii

\begin{tabular}{|c|c|c|c|c|c|c|c|c|c|c|c|c|}
\hline & FWt & FL & FW & PWt & RWt & SKWt & EWt & $\mathrm{P} \%$ & SK\% & FS & FA & $\mathrm{FR}$ \\
\hline FWt & 1.000 & & & & & & & & & & & \\
\hline $\mathrm{FL}$ & $0.736^{\star *}$ & 1.000 & & & & & & & & & & \\
\hline FW & $0.794^{\star *}$ & 0.287 & 1.000 & & & & & & & & & \\
\hline PWt & $0.825^{\star *}$ & $0.484^{\star *}$ & $0.808^{\star *}$ & 1.000 & & & & & & & & \\
\hline RWt & $0.863^{\star *}$ & $0.525^{\star \star}$ & $0.815^{\star \star}$ & $0.745^{\star *}$ & 1.000 & & & & & & & \\
\hline SKWt & $0.664^{* *}$ & $0.564^{\star *}$ & $0.457^{\star \star}$ & $0.437^{\star \star}$ & $0.394^{\star *}$ & 1.000 & & & & & & \\
\hline EWt & $0.950^{\star \star}$ & $0.783^{\star \star}$ & $0.646^{\star \star}$ & $0.633^{\star \star}$ & $0.750^{\star \star}$ & $0.651^{\star *}$ & 1.000 & & & & & \\
\hline $\mathrm{P} \%$ & 0.105 & -0.081 & $0.336^{*}$ & $0.632^{\star \star}$ & 0.095 & -0.101 & -0.146 & 1.000 & & & & \\
\hline SK\% & $-0.318^{\star}$ & -0.199 & $-0.325^{\star}$ & $-0.395^{\star *}$ & $-0.435^{* *}$ & $0.457^{\star *}$ & $-0.295^{*}$ & -0.292 & 1.000 & & & \\
\hline FS & 0.184 & $0.494^{\star \star}$ & -0.168 & 0.005 & -0.040 & 0.196 & $0.300^{\star}$ & -0.174 & -0.066 & 1.000 & & \\
\hline FA & 0.146 & $0.564^{\star *}$ & -0.221 & -0.029 & -0.047 & 0.102 & 0.267 & -0.205 & -0.021 & 0.270 & 1.000 & \\
\hline FR & 0.071 & 0.143 & -0.075 & -0.054 & 0.025 & -0.016 & 0.143 & -0.181 & -0.106 & 0.080 & 0.203 & 1.000 \\
\hline
\end{tabular}

**. Correlation is significant at the 0.01 level (2-tailed) 
*. Correlation is significant at the 0.05 level (2-tailed)

Table 5. Principle component analysis of the morphological traits used to assess the diversity of Balanites roxburghii

\begin{tabular}{|llllll|}
\hline & PC 1 & PC 2 & PC 3 & PC 4 & PC 5 \\
\hline Eigen values & 5.189 & 2.339 & 1.483 & 1.036 & 0.813 \\
\hline Proportion of variance (\%) & 43.244 & 19.492 & 12.361 & 8.633 & 6.773 \\
\hline Cumulative variance (\%) & 43.244 & 62.736 & 75.097 & 83.730 & 90.503 \\
\hline Eigenvectors & & & & & \\
\hline Traits & & & & & \\
\hline FWt & 0.992 & 0.036 & 0.051 & -0.057 & -0.030 \\
\hline FL & 0.756 & 0.520 & -0.149 & 0.202 & 0.038 \\
\hline FW & $\mathbf{0 . 8 1 1}$ & -0.446 & 0.166 & -0.154 & -0.029 \\
\hline PWt & $\mathbf{0 . 8 5 9}$ & -0.392 & -0.032 & 0.207 & 0.210 \\
\hline RWt & $\mathbf{0 . 8 7 2}$ & -0.209 & -0.025 & -0.250 & -0.176 \\
\hline SKWt & 0.631 & 0.331 & $\mathbf{0 . 6 6 1}$ & 0.058 & 0.166 \\
\hline EWt & $\mathbf{0 . 9 2 1}$ & 0.272 & 0.005 & -0.131 & -0.130 \\
\hline P\% & 0.184 & -0.692 & -0.159 & 0.507 & 0.429 \\
\hline SK\% & -0.360 & 0.345 & $\mathbf{0 . 8 1 2}$ & 0.057 & 0.258 \\
\hline FS & 0.198 & $\mathbf{0 . 5 9 2}$ & -0.224 & 0.432 & -0.284 \\
\hline FA & 0.161 & $\mathbf{0 . 6 6 0}$ & -0.340 & 0.210 & 0.312 \\
\hline FR & 0.064 & 0.321 & -0.378 & -0.592 & 0.511 \\
\hline
\end{tabular}

Table 6. Mean values of quantitative traits used in the cluster identification of Balanites roxburghii accessions

\begin{tabular}{|lllll|}
\hline & Cluster 1 & Cluster 2 & Cluster 3 & Cluster 4 \\
\hline FWt (g) & $23.48 \pm 0.59$ & $16.68 \pm 0.52$ & $32.29 \pm 1.12$ & $\mathbf{3 3 . 6 7 \pm 1 . 3 0}$ \\
\hline FL (cm) & $4.84 \pm 0.13$ & $4.12 \pm 0.12$ & $\mathbf{6 . 4 7 \pm 1 . 1 9}$ & $5.55 \pm 0.30$ \\
\hline FW (cm) & $3.57 \pm 0.04$ & $3.21 \pm 0.05$ & $3.65 \pm 0.21$ & $\mathbf{4 . 0 4 \pm 0 . 1 3}$ \\
\hline PWt (g) & $5.59 \pm 0.19$ & $3.50 \pm 0.23$ & $5.70 \pm 0.64$ & $\mathbf{8 . 1 0} \pm 0.51$ \\
\hline RWt (g) & $3.80 \pm 0.14$ & $3.14 \pm 0.14$ & $4.42 \pm 0.25$ & $\mathbf{6 . 4 2 \pm 0 . 2 6}$ \\
\hline SKWt (g) & $2.11 \pm 0.08$ & $1.53 \pm 0.10$ & $\mathbf{3 . 5 4 \pm 0 . 3 3}$ & $2.37 \pm 0.20$ \\
\hline EWt (g) & $11.95 \pm 0.58$ & $8.54 \pm 0.31$ & $\mathbf{1 8 . 6 2 \pm 1 . 7 2}$ & $16.77 \pm 0.62$ \\
\hline P\% (\%) & $\mathbf{2 4 . 2 0 \pm 1 . 1 7}$ & $20.71 \pm 1.00$ & $17.72 \pm 2.62$ & $23.99 \pm 0.78$ \\
\hline SK\% (\%) & $9.07 \pm 0.39$ & $9.32 \pm 0.66$ & $\mathbf{1 0 . 9 5 \pm 0 . 6 4}$ & $7.05 \pm 0.54$ \\
\hline
\end{tabular}

\section{Figures}




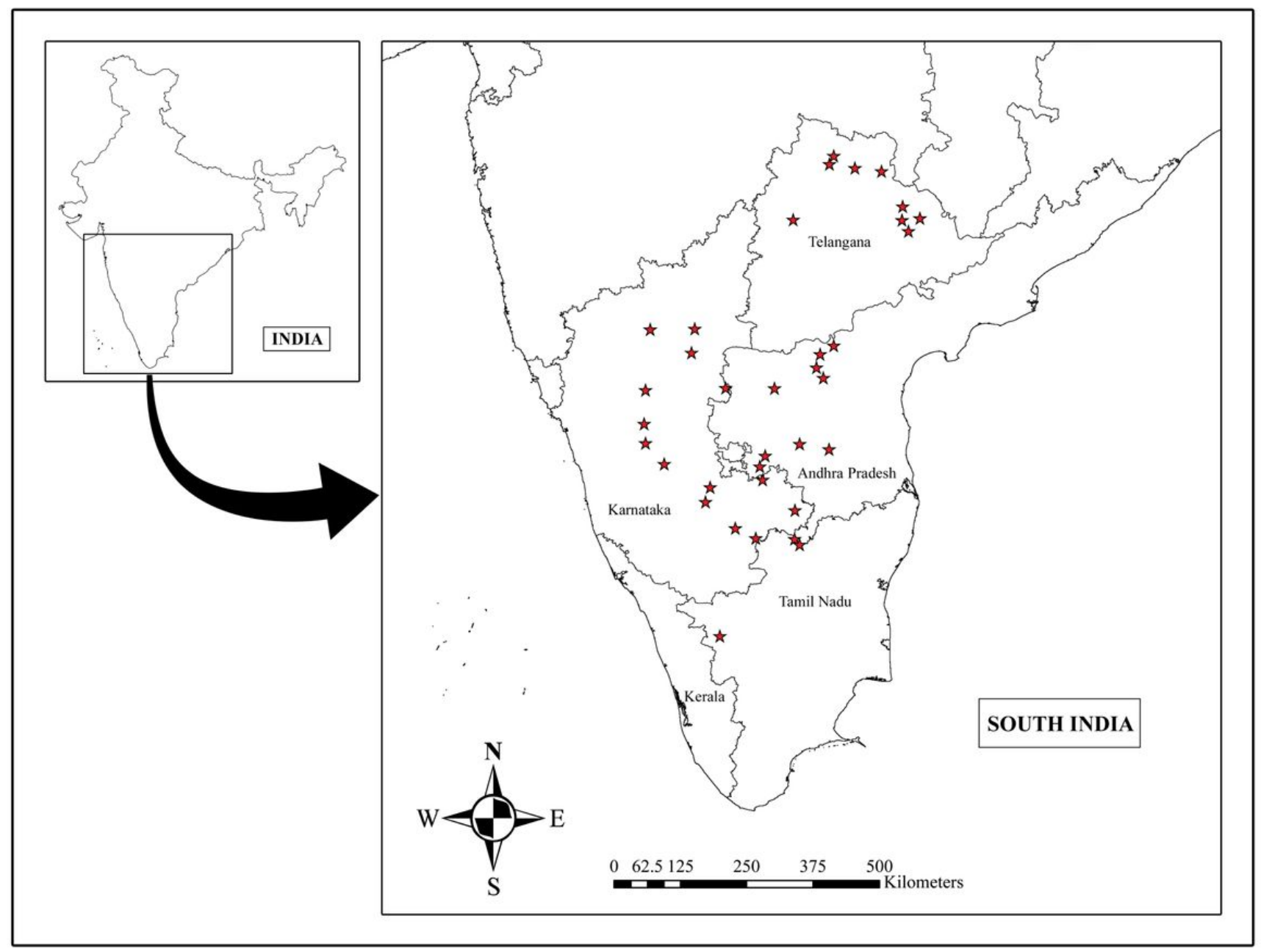

Figure 1

Map of Southern India showing the collection sites of Balanites roxburghii 


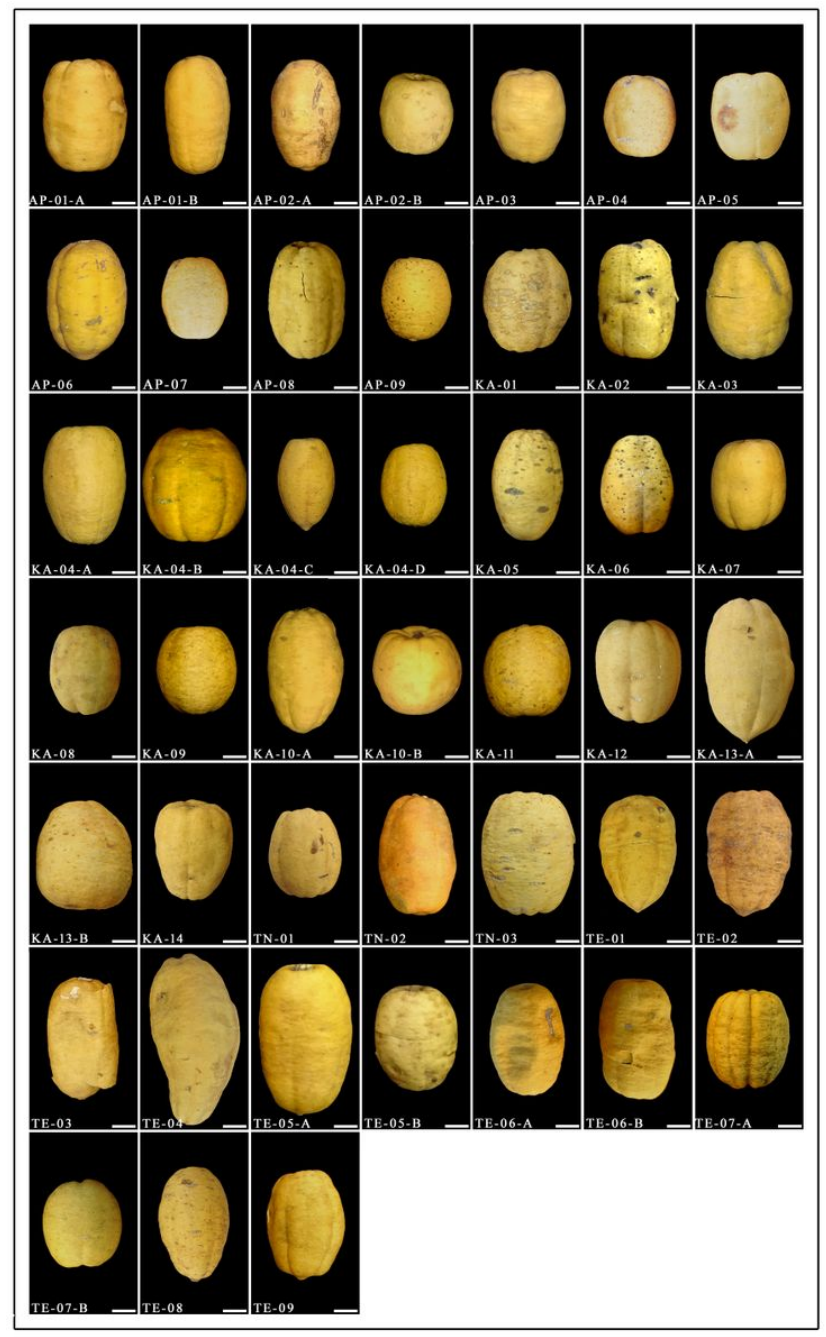

Figure 2

Morphological variability of fruits of Balanites roxburghii accessions collected from Southern India. Scale: $1 \mathrm{Bar}=1 \mathrm{~cm}$ 


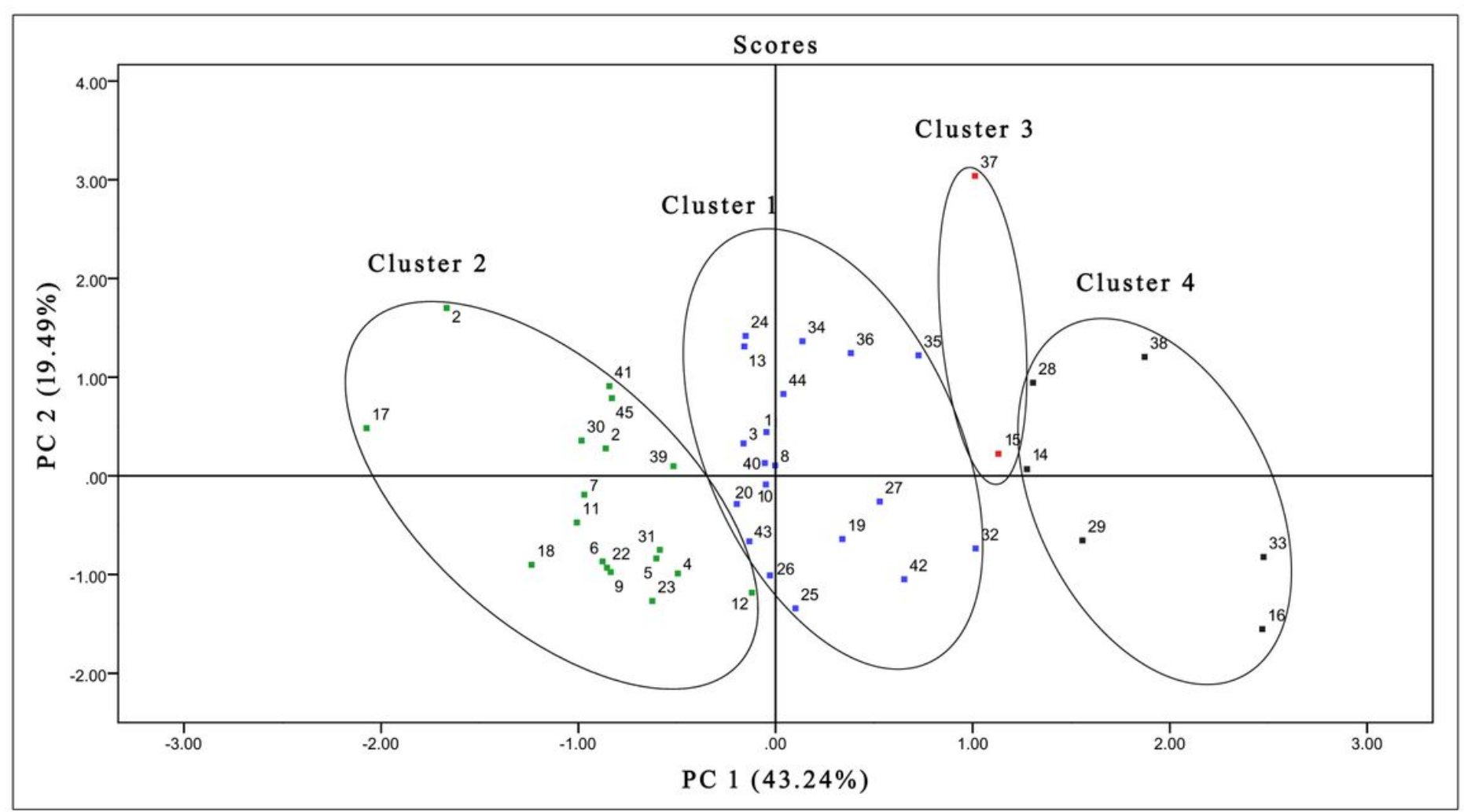

Figure 3

The cluster diagram was constructed using the k-means clustering method and accessions were scattered using the scores of the first two principal component axes. Each numerical number represents an accession as given in Table 3 